\title{
IRREGULARIDAD, INVALIDEZ E INEFICACIA EN EL CONTEXTO DE LA NULIDAD PROCESAL*
}

\section{Felipe Gorigoitía AвBotT**}

RESUMEN: El presente artículo busca proponer algunas bases conceptuales que se estiman útiles para el entendimiento de la nulidad en el proceso civil. Para ello, se distinguen y analizan tres conceptos -irregularidad, invalidez e ineficacia- que sirven para describir el camino que sigue un acto procesal defectuoso, desde que se determina que no se corresponde con el modelo fijado por el ordenamiento jurídico (irregularidad) hasta que se hace ineficaz. Se entiende a la nulidad como una técnica que sirve para hacer ineficaces actos emanados del órgano jurisdiccional, en general pero no exclusivamente, debido a su invalidez y que debe emplearse solo en caso de no haber operado la subsanación o la convalidación del defecto procesal.

PALABRAS CLAVE: Nulidad procesal - invalidez - irregularidad - ineficacia - inadmisión.

\section{IRREGULARITY, INVALIDITY AND INEFFECTIVENESS IN THE CONTEXT OF PROCEDURAL NULLITY}

ABSTRACT: This article aims to propose some conceptual bases that are useful to understand the nullity in a civil proceeding. To this effect, three concepts are distinguished and analyzed: irregularity, invalidity and ineffectiveness, that describe the defective way of a procedural act, since it is determined that it does not correspond with the prototype model granted by the legal system until it becomes ineffective. The nullity is understood as a technique used to render ineffective acts issued by the court, usually but not exclusively, due to its invalidity and it should be used only in case of the non working ratification or correction of the defective procedural act.

KEY WORDS: procedural nullity - invalidity - irregularity - inefficiency - rejection.

Fecha de recepción:13 de agosto de 2012.

Fecha de aprobación: 17 de marzo de 2013.

** Abogado, Doctorando Universitat Pompeu Fabra, Profesor Adjunto de Derecho Procesal, Universidad de Valparaíso. Correo electrónico: felipe.gorigoitia@uv.cl. Agradezco los comentarios de Andrés Peña Adasme, que han ayudado a mejorar sustancialmente este artículo. 
Sumario: 1) Introducción. 2) La irregularidad como punto de partida. (2.1) Noción de irregularidad. (2.2) Características y consecuencias del juicio de regularidad. (2.3) Modelo normativo que determina la regularidad de los actos. (2.3.1) Es un modelo procesal. (2.3.2) Es un modelo que no se agota en la regulación inmediata del acto. 3) Determinación de la validez de los actos irregulares.3.1) Finalidad del juicio de validez. 3.2) La invalidez como resultado de un juicio valorativo, dinámico y particularizado. 3.3) Casos en los que la irregularidad equivale a la invalidez. 4) La ineficacia. (4.1) Noción y distinción de la invalidez. (4.2) El paso de la invalidez a la ineficacia. (4.2.1) No toda invalidez implica ineficacia. (4.2.2) Formas de implementar la ineficacia; (4.2.3). Alcance de la ineficacia: la nulidad derivada y el principio de conservación. (4.2.3.1) La nulidad derivada. (4.2.3.2) El principio de conservación. 5) Conclusiones. 6) Bibliografia

\section{1) INTRODUCCIÓN}

El presente artículo tiene por objetivo explicar ciertas distinciones que resultan básicas para un correcto entendimiento de lo que tradicionalmente se ha conocido como la nulidad procesal. Aunque podrían parecer distinciones simplemente semánticas, tras ellas hay conceptos que no se han diferenciado con total claridad por nuestra doctrina y que son indispensables para describir de forma precisa cualquier sistema anulatorio moderno.

El esquema que se propone descansa sobre tres ejes: la irregularidad, la invalidez y la ineficacia. Los tres constituyen una especie de camino por el que transita un defecto procesal desde su génesis hasta su eliminación por el sistema. Para explicar este recorrido se analizará, primeramente, qué es y cómo se determina la irregularidad, para luego estudiar qué actos irregulares merecen la calificación de inválidos y cómo estos últimos son superados por el sistema, sea a través de su eliminación (vía nulidad o inadmisión) o de otros medios (vía convalidación o subsanación).

Este trabajo parte de un concepto de nulidad procesal bastante asentado en la doctrina espańola, pero poco difundido en la doctrina nacional, que entiende a la nulidad como una técnica de protección y no como una condición intrínseca de un acto procesal ni como una sanción ${ }^{1}$. De ella se pueden derivar dos consecuencias que determinan el contenido de este trabajo: (a) Lo que protege un sistema de invalidez son ciertos valores especialmente valiosos para un sistema, normal, pero no exclusivamente,

La deficiencia ha sido subsanada con brillantez por Carrasco Poblete, Jaime (2011). "La nulidad procesal como técnica protectora de los derechos y garantías de las partes en el derecho procesal chileno". Revista de Derecho Universidad Católica del Norte, Vol. 18, No 1, p. 49-84. 
relacionados con las garantías procesales de rango constitucional y no las formas ni los requisitos procesales; y (b) La nulidad procesal no es más que una de las técnicas que sirve para hacer ineficaces los actos inválidos ${ }^{2}$.

\section{2) LA IRREGULARIDAD COMO PUNTO DE PARTIDA}

\section{1) NOCIÓN DE IRREGULARIDAD}

El término irregularidad procesal es de uso habitual dentro de quienes se ocupan del tema de la invalidez procesal. Aunque con una base conceptual común, se ha utilizado principalmente de dos formas: como una categoría de actos que sufren defectos menores y como un género amplio en el que se incluye todo acto imperfecto, sea válido o no ${ }^{3}$.

La primera acepción es bastante recurrente, en especial entre quienes hacen un acercamiento tradicional al tema de la nulidad. Se emplea para hacer referencia a aquellos actos afectados por defectos que no inciden en la validez, aunque sí pueden producir otras consecuencias gravosas para el autor ${ }^{4}$. Se describe como una categoría de actos en que se engloban los defectos de menor gravedad, reservándose para los más graves la anulabilidad, la nulidad absoluta y, si es que cabe, la inexistencia.

La segunda forma de utilizar la palabra irregularidad es identificándola con todo acto defectuoso. Consistiría en un género en el que se englobaría a todas las actuaciones imperfectas, sean estas válidas o inválidas, siendo su única característica determinante la separación con un ideal de acto. Dentro de este género se podrían reconocer los actos meramente irregulares de los inválidos y, de admitirse como categoría, de los inexistentes $^{5}$. En este trabajo se emplea el término en esta segunda acepción, por lo que cuando se habla de irregularidad se quiere denominar a aquella situación en la que hay una discordancia entre el acto realizado y el modelo normativo.

2 Sobre ambos puntos, véase CARrasco (2011) 49 y ss.

3 Esta prevención ya la hace Serra Domínguez, Manuel (1969) "Actos procesales irregulares". En Estudios de derecho procesal. Barcelona: Ariel, p. 468.

4 Por todos, Carnelutti, Francesco (1999) Lecciones sobre el proceso penal. Buenos Aires: El Foro, p. 183; y SERra (1969) 468.

5 En este sentido ya lo entendía Villar y Romero al definir irregularidad del acto como "la realización del mismo sin el absoluto y debido cumplimiento de todos los requisitos exigidos en cada caso" [en Villar y Romero, José M. (1954). "Irregularidad y nulidad de los actos procesales administrativos". Revista de Derecho Procesal, Vol. 3, p. 319]. En la misma línea, más recientemente, Andrés Ciurana, Baldomero (2005) La invalidez de las actuaciones en el proceso civil. Valencia: Tirant lo Blanch, p. 134; y Barona Villar, S. en Montero Aroca, Juan, et al. (2008) Derecho jurisdiccional, I. Parte general. 16 edición. Valencia: Tirant lo Blanch, p. 423. 


\section{2) CARACTERÍSTICAS Y CONSECUENCIAS DEL JUICIO DE REGULARI- DAD}

Desde un punto de vista lógico, el primer examen al que se somete cualquier acto procesal es relativo a su regularidad, es decir, de cumplimiento del modelo normativo al que se debe ceńir. Este juicio de regularidad tiene básicamente dos características que lo definen: (a) es meramente formal; y (b) es binario.

(a) El análisis que se debe efectuar al momento de determinar la regularidad de un acto es en sí formal, pues no supone ni requiere valoración alguna para determinar su resultado. Es una mera contraposición entre el acto y el modelo, que arrojará como resultado una constatación de si el acto en particular se adecua al patrón que debe seguir ${ }^{6}$.

(b) El juicio es binario, en el sentido que solo se pueden desprender dos resultados de él: la regularidad o irregularidad del acto. Si la correspondencia entre el modelo normativo y el acto analizado es completa, el acto se reputará regular, mientras que si se detectan desajustes, no lo será. No caben respuestas intermedias, sin perjuicio de que, a posteriori, se valore la gravedad del acto para determinar la validez del mismo.

Las consecuencias de este juicio son especialmente relevantes, pues la irregularidad es condición necesaria -aunque no suficiente- de la invalidez, lo que implica que: (a) no toda irregularidad generará invalidez; y (b) toda invalidez presupone una irregularidad.

(a) La primera de las implicancias es bastante obvia, ya que lo contrario equivaldría a un sistema formalista en extremo ${ }^{7}$. En este aspecto, si se constata la irregularidad del acto, habrá solo una consecuencia que consiste en que el acto irregular será sometido al análisis de relevancia del defecto que implica el juicio de validez, pudiendo resultar que el mismo sea válido o inválido según la valoración que en ese momento se haga. Siguiendo a Binder, se puede afirmar que lo que se produce cuando se detecta el desajuste entre el acto y el modelo es un aviso en el sistema acerca de la posible afectación de una garantía protegida por ella que provoca que el mismo sea sometido al análisis posterior ya no de conformidad con

6 Utilizando la denominación de legalidad en vez de regularidad, Nieto afirma que "el operador jurídico contrasta acto y norma y a su vista constata o una concordancia (legalidad) o una discordancia (ilegalidad)" [Nieto, A. en el "Estudio preliminar". En Beladiez Rojo, Margarita (1994) Validez y eficacia de los actos administrativos. Madrid: Marcial Pons, p. 10]. Es lo que tradicionalmente se reconoce como "principio de trascendencia", entendido por Couture como "que las nulidades no tienen por finalidad satisfacer pruritos formales, sino enmendar los perjuicios efectivos que pudieran surgir de la desviación de los métodos de debate cada vez que esta desviación suponga restricción de las garantías a que tienen derecho los litigantes" [Couture, Eduardo J. (2002) Fundamentos del derecho procesal civil. Montevideo: B de F, p. 318]. 
el modelo, sino de validez de acuerdo a los parámetros que establece cada ordenamiento ${ }^{8}$.

(b) La segunda consecuencia de lo afirmado resulta más controvertida en la doctrina. Que la invalidez tenga como presupuesto la irregularidad significa que todo acto procesal inválido debe ser previamente irregular y que, por lo tanto, todo acto regular es automáticamente válido, por lo que si el juicio de validez para el acto irregular es valorativo y separado del de regularidad, para el acto regular sería solo fáctico, pues se vería absorbido por este último, ya que, una vez constatada esta calidad, no cabría cuestionar la validez del acto, incluso si luego se detectara alguna afectación relevante para el mismo sistema ${ }^{9}$. Aunque una postura como la esbozada puede parecer repugnante a los criterios más básicos de justicia y de primacía de las garantías constitucionales ${ }^{10}$, el tema adquiere su justa dimensión y se explica cuando se deja de lado la idea de un modelo normativo constituido solo por normas procedimentales y se le concibe de forma más compleja, integrado, entre otros elementos, por las mismas garantías que inspiran al sistema, como se verá en el apartado siguiente.

En nuestro proceso civil, esto tiene expresión en el artículo $83 \mathrm{CPC}$, inciso primero, al establecer como requisito de la nulidad la existencia de "un vicio que irrogue a alguna de las partes un perjuicio reparable solo con la declaración de nulidad". Una demostración de la reticencia del legislador entender como nulidad a casos en que no haya irregularidad son los incidentes especiales regulados en los artículos 79 y 80 CPC, que buscan dejar sin efecto actuaciones realizadas cuando hubo fuerza mayor o falta de emplazamiento por un hecho no imputable al notificado. En estos casos, se elude el término nulidad y se emplea el de "rescisión", para reflejar la excepcionalidad de estas situaciones en las que, privilegiando el ejercicio del derecho de defensa por sobre la seguridad jurídica, se produce ineficacia sin necesidad de un defecto procesal. Aunque en nuestro or-

8 Binder, Alberto M. (2000) El incumplimiento de las formas procesales: Elementos para una critica a la teoría unitaria de las nulidades en el proceso penal. Buenos Aires: Ad-Hoc, p. 9495.

9 En el mismo sentido, Andrés Ciurana afirma que "En definitiva, presupuesto de la invalidez es siempre la divergencia de la conducta de un sujeto que aspira a producir efectos en el proceso y la norma procesal que ordena dicha conducta y regula sus efectos. Esta irregularidad no guarda relación necesaria con la invalidez, pues esta última es fruto de una valoración de la irregularidad" [ANDrés (2005) 134]. Comparte esta postura BARONA VILLAR cuando afirma que en "el origen de toda invalidez se encuentra una divergencia entre la estructura del acto, tal como se ha realizado en la práctica, y el esquema previsto por la norma” [en Montero Aroca, et al. (2008) 423]. Fuera del derecho procesal, Nieto afirma que "todas las invalideces son consecuencia de una ilegalidad; pero no todas las ilegalidades arrastran la invalidez" [en Beladiez (1994) 11].

10 Así, Ramos Méndez, Francisco (2005) El sistema procesal español. 7a edición. Barcelona: Atelier, p. 292, afirma que la indefensión es "más bien un parámetro constitucional de referencia, que previene de un resultado negativo a evitar en todo caso, con o sin infracción de preceptos procesales". 
denamiento los efectos de ella y de la nulidad son los mismos, es relevante tener presente esta categoría, porque en ella, a diferencia de lo que ocurre en casos en los que hay invalidez como antecedente, es perfectamente concebible una vuelta atrás que no implique una repetición exacta de todo lo obrado ${ }^{11}$.

\section{3.) MODELO NORMATIVO QUE DETERMINA LA REGULARIDAD DE LOS ACTOS}

\subsection{1) Es un modelo procesal}

Cada vez que se habla de un modelo normativo se está haciendo referencia a un ideal de acto que se encuentra plasmado en la ordenación procesal. Se trata del conjunto de presupuestos y requisitos que se exige para que una determinada actuación procesal se considere como regular, como ajustada al ordenamiento. La determinación de los elementos que configuran el modelo nace de la ponderación que el legislador hace de los fines que se proponen, las garantías que se deben preservar, la eficiencia del proceso y otros factores, esperablemente, basado en la experiencia y realidad cultural de la sociedad respectiva ${ }^{12}$, presumiendo que, con la configuración que se propone, se ven bien resguardados todos los intereses en juego ${ }^{13}$.

Este modelo o esquema, que se establece por el ordenamiento y que permite apreciar la regularidad del acto, es de carácter procesal. Es decir, está constituido por una serie de elementos que no dicen relación con el contenido del acto, sino con el modo de proponerlo. En muchas ocasiones, se ha identificado lo procesal con lo formal, lo que, en este ámbito, implicaría una configuración del modelo normativo solo con los aspectos exteriores del acto procesal ${ }^{14}$. Sin embargo, en la actualidad hay concordancia en el sentido de que existen elementos procesales no formales que determinan la regularidad del acto, en especial referentes a la capacidad de

11 Es lo que ocurre en la Ley de Enjuiciamiento Civil española (artículos 501 a 508). En el caso espańol, esta rescisión a instancias del litigante rebelde más que generar ineficacia de las actuaciones, permite un procedimiento más breve en el que se dictará una nueva sentencia, que constituye una suerte de retroacción de las actuaciones para que el rebelde pueda ejercer su derecho de defensa, pero sin anular los actos de prueba ya realizados.

12 Una constatación de este tipo hace Bedaque, José dos Santos (2010) Efectividad del proceso y técnica procesal. Traducción de Monroy Palacios, Juan José y Delgado Suárez, Christian. Lima: Communitas, p. 83.

13 Giovanardi, Carlo A. (1987). "Sullo scopo dell'atto processuale, in relazione alla disciplina della nullità”. Rivista di diritto civile, II, p. 281.

14 En este sentido, Prieto-Castro define como falta de un acto de las partes o del tribunal "al defecto de que adolece cuando en su disposición externa y en su realización no se han cumplido los requisitos de forma exigidos por la ley" [Prieto-Castro y Ferrándiz, Leonardo (1988) Derecho procesal civil. Madrid: Tecnos, p. 134]. 
las partes y la competencia del tribunal, que no cabe que sean incluidos dentro de esta noción, aun cuando se le entienda en un sentido amplio ${ }^{15}$.

Si el modelo normativo es procesal, los defectos que pueden afectar su perfección son de la misma naturaleza, lo que supone que nada que tenga que ver con el fondo del acto puede terminar por generar su irregularidad. Solo la infracción de preceptos procesales, que en este modelo se plasman como parte de los presupuestos y requisitos por cumplir, puede generar una irregularidad eventualmente relevante.

\subsection{2) Es un modelo que no se agota en la regulación inmediata del acto}

El reconocimiento del esquema normativo que determine los presupuestos y requisitos que debe cumplir un determinado acto es una tarea más dificultosa de lo aparente no solo en el ámbito del derecho procesal, sino, en general, en todo el ordenamiento jurídico ${ }^{16}$. De entrada, debe descartarse que el modelo a que se está haciendo referencia pueda identificarse con la sola regulación de las normas que más inmediatamente le configuran. Dados los elementos que a continuación se verán, cualquier descripción de un esquema que se agote en la disposición de regulación más inmediata será incompleta ${ }^{17}$.

En el área procesal, hay dos elementos que inciden especialmente en que el modelo normativo esté lejos de agotarse en la regulación más próxima y sea de más compleja reconstrucción: (a) la necesidad de entender al acto procesal como un acto integrado al proceso; y (b) los requisitos que, más allá de la literalidad, imponen las garantías constitucionales.

(a) Uno de los factores más claramente diferenciadores del acto procesal respecto a cualquier otro tipo de acto jurídico es lo inseparable que resulta el acto del proceso como unidad mayor a la que pertenece. Esta característica adquiere una relevancia especial en el tema de la determinación del modelo procesal, tal como se ha ocupado de poner de manifiesto SATTA, quien descarta que el modelo del acto sea lo descrito en la norma particular, y afirma, en cambio, que se debe identificar con toda la disciplina del proceso ${ }^{18}$.

Esta situación no impide que se pueda apreciar la invalidez de un acto considerado como tal, sino que obliga a ampliar la perspectiva preo-

\footnotetext{
15 En este sentido, entre muchos, Hernández Galilea, Jesús M. (1995) La nueva regulación de la nulidad procesal: El sistema de ineficacia de la LOPJ. Oviedo: Fórum, p. 181.

16 Así lo repara, dentro del derecho privado, Delgado Echeverría, Jesús (2006). "El concepto de validez de los actos jurídicos de derecho privado". Anuario de derecho civil, Vol. 58, No 1, p. 33.

17 En este sentido, Hernández (I995) 103; y Andrés (2005) 134.

18 Satta Salvatore y Punzi, Carmine (1996) Diritto processuale civile. 12a edición. Padova: Cedam, p. 292.
} 
cupándose ya no solo de la validez de este en particular, sino del proceso como un todo digno de protección más allá de la pura sumatoria de los $\operatorname{actos}^{19}$. En consecuencia, el juicio de regularidad de un acto procesal requerirá un análisis de la integración del acto al proceso, cuestión que impone la incorporación al modelo de variables como la composición y constitución del tribunal, el principio de inmediación o el orden de los actos procesales ${ }^{20}$.

(b) A estas alturas del desarrollo doctrinal, parece innecesario seguir remarcando la influencia que tienen las garantías constitucionales en la configuración del proceso. Si todo el sistema de invalidez del proceso tiene como objeto primordial velar por el respeto a las garantías constitucionales, resulta lógico que estas sirvan, además de para determinar la validez del acto, para configurar cómo debe realizarse, incluso más allá de la regulación expresa que se pueda encontrar. Concretamente, la incorporación de las garantías constitucionales como variable que contribuye a la construcción del modelo normativo impone ciertas condiciones y requisitos a los actos procesales que no se encuentran de forma expresa en la ley, pero que se pueden deducir de los estándares que estas imponen y que, en algunos casos, se han ido reconociendo por la jurisprudencia ${ }^{21}$.

El reconocimiento de requisitos en el ordenamiento jurídico que nacen directamente de las garantías constitucionales no es más que una verificación de la insuficiencia de la regulación legal. Parte de la constatación del operador de que la aplicación del modelo normativo que se puede reconstruir con la sola utilización de la ley, incluso considerando la perspectiva del proceso y no solo del acto en particular, permite la existencia de actos procesales que pueden producir la vulneración de garantías constitucionales. Esta situación impone la construcción de un modelo más exigente que recoja no ya las valoraciones de la ley sino del sistema jurídico en el que el acto en particular se debe insertar de forma armónica con las reglas, pero también con los valores vigentes del mismo ${ }^{22}$.

Hernández (1995) 105.

ANDRÉs (2005) 152.

21 En un sentido similar, Hernández (I995) 175, afirma que “(...) la regularidad de los actos procesales no depende exclusivamente de la escrupulosa observancia de las normas de procedimiento, sino que en cada momento debe atenderse, por encima de ellas, a la protección de los derechos fundamentales de las partes en el proceso".

22 Sobre el punto, véase Marinoni, Luiz G.; Pérez Ragone, Álvaro y NúNez OJeda, Raúl (2010) Fundamentos del proceso civil: Hacia una teoría de la adjudicación. Santiago de Chile: Abeledo-Perrot, p. 90 y ss. En nuestro derecho esta "constitucionalización" del modelo procesal es especialmente patente en lo relativo a la exigencia de motivación de las sentencias. A partir del reconocimiento de ella como un derecho de rango constitucional, no solo se ha reforzado la exigencia de motivación de las sentencias definitivas, sino, incluso, se ha declarado la obligatoriedad de la motivación incluso en casos en los que la ley parecía haberla dispensado. Es lo que ha ocurrido en los casos en que el Tribunal Constitucional (TC) ha declarado inaplicable por inconstitucional el inciso antepenúltimo del artículo $768 \mathrm{del}$ 
Lo recién expuesto permite la revisión más precisa de dos afirmaciones que se han hecho con anterioridad y que, aunque correctas, merecen alguna mayor explicación. La primera de ellas dice relación con la consideración de que el juicio de regularidad es meramente formal. Aquello es efectivo, pero no implica que la construcción del modelo al que se le debe contrastar el acto no tenga un importante componente valorativo. En el momento en que se admite que las garantías constitucionales condicionan la configuración del modelo normativo estableciendo requisitos que la ley no exige de forma expresa, este componente gana un espacio importante en la construcción del mismo. Esto se traduce en un conjunto de requisitos que están pensados para la protección de garantías, pero no en el juicio propiamente tal, que sigue siendo objetivo, a partir, claro está, del modelo construido.

La segunda afirmación digna de revisión es la que se ha referido al juicio afirmativo de regularidad como equivalente al de validez. Considerando la composición del modelo por garantías constitucionales, el que ambos juicios se confundan no parece tan extraño, pues en el modelo ya están incorporadas las mismas valoraciones que después servirán para el juicio de validez. De alguna manera, este modelo se transforma en un catálogo de requisitos cuyo cumplimiento asegura la conformidad del acto con el ordenamiento jurídico en general, incluidas, evidentemente, las garantías constitucionales. La separación, entonces, del juicio de irregularidad del de invalidez vendría a ser una suerte de segunda oportunidad para el acto en el que, constatada su disconformidad con el modelo, se valora si, a pesar de este hecho, el mismo merece o no la protección del ordenamiento jurídico.

En principio, la irregularidad como tal no requiere de regulación legal. No siendo un tipo de acto que por sí genere una consecuencia diversa al acto regular, no es indispensable que goce propiamente de un estatuto legal ${ }^{23}$. Sin perjuicio de lo anterior, nuestro CPC en algunos casos es-

CPC en cuanto este excluye la posibilidad de recurrir de casación en la forma por omisión o insuficiencia en la motivación de la sentencia definitiva en procedimientos o reclamaciones regidas por leyes especiales. Sobre el punto, el TC ha dicho que "(...) la motivación de la sentencia es connatural a la jurisdicción y fundamento indispensable para su ejercicio. Constituye, a la vez que un deber del juzgador, un derecho para el justiciable. Es inherente al derecho a la acción y, por ende, a la concreción de la tutela judicial efectiva; elementos propios de las garantías de un procedimiento racional y justo, cuya ausencia o limitación vulnera la exigencia constitucional y autoriza declarar la inaplicabilidad del precepto objetado" (sentencia de 22 de junio de 2010, rol 1373-2009-INA) En el mismo sentido se ha manifestado en la sentencia de 25 de agosto de 2011, rol 1873-2010-INA. Por sentencia de 5 de julio de 2012, rol 2034-2011 INA, un requerimiento de inaplicabilidad por el mismo fundamento fue rechazado al alcanzarse un empate entre quienes estaban por estimarlo y los que estaban por desestimarlo,

23 En términos parecidos, Di Geronimo, Paolo (2006) La nullità degli atti nel processo penale. Milano: Giuffrè, p. 30. 
tablece expresamente la validez de actuaciones irregulares, atribuyendo otras consecuencias a la irregularidad, como ocurre de omitir el ministro de fe la remisión de cartas certificadas de los artículos 46, 233 y 450 CPC.

\section{3) DETERMINACIÓN DE LA VALIDEZ DE LOS ACTOS IRREGULARES}

\section{1) FINALIDAD DEL JUICIO DE VALIDEZ}

Ya se decía que si se constata la irregularidad de un acto procesal, procede hacer un análisis de su validez. Mientras este juicio no se realice, el acto procesal irregular se encuentra en un estado precario que puede derivar o en la determinación de su validez, y por lo tanto, su perfecta aptitud para producir efectos, o de su invalidez, con las consecuencias que de ella se deriva ${ }^{24}$.

Para comprender esto es necesario determinar qué es la validez, es decir, qué quiere decir que un acto es válido o inválido. La forma de ver la validez o invalidez que surge más adecuada en la descripción del sistema es la de Beladiez Rojo, que concibe al juicio de validez como aquel que sirve para determinar si un acto está conforme a Derecho y, por lo tanto, si debe ser protegido por este, lo que lleva a entender la invalidez como "la calificación que debe otorgarse al acto no ya cuando exista un desajuste estructural entre el acto y la norma, sino cuando el Derecho considera que este desajuste estructural no debe ser protegido" 25 .

Entender la validez de la forma expuesta impone que el análisis que se haga -a partir de un parámetro que es variable de acuerdo a cada ordenamiento- tenga por objetivo determinar si la imperfección presente constituye o no un obstáculo para que el acto pueda ser considerado de igual forma que el regular. En otras palabras, la cuestión es si el acto defectuoso, a pesar de su imperfección, debe o no gozar del mismo estatus del que gozaría si se hubiese apegado al modelo normativo impuesto. Si la conclusión es positiva, implica que su conservación está garantizada por la ley, pues se ha creado una situación que se juzga digna de tutela por el Derecho. Por el contrario, si se considera inválido el acto, este, al menos mientras permanezca en ese estado, no gozará de esta garantía del ordenamiento ${ }^{26}$.

\footnotetext{
24 Algo parecido plantea Mancinelli, Roberto (1957). "Nullità degli atti processuali penali". Novissimo Digesto Italiano, XI. Torino: UTET, p. 488.

25 Beladiez (1994) 56. Sigue esta postura, citándola, Andrés (2005) 78.

26 Beladiez (1994) 57.
} 


\section{2) LA INVALIDEZ COMO RESULTADO DE UN JUICIO VALORATIVO, DINÁMICO Y PARTICULARIZADO}

A diferencia del juicio de regularidad, cuando se debe determinar la validez de una determinada actuación, el análisis no consiste en constatación de hechos sino en la valoración de la desviación ya detectada cuando se apreció la imperfección. En este sentido, puede afirmarse que este juicio es valorativo, y no formal, debido a que se hace necesario recurrir a parámetros que exceden la mera observación del acto para determinar su validez. Esta posición ha sido sostenida por algunos autores, ya sea considerando a la invalidez un juicio de valor o una calificación jurídica, ambos conceptos en contraste a la mera apreciación objetiva que supone la determinación de la irregularidad. Así, Nieto afirma que "en definitiva, pues nos encontramos ante dos juicios sucesivos: un juicio de ilegalidad, primero, que es el resultado de una constatación; y un segundo y posterior juicio de invalidez, que es el resultado de una valoración (o calificación) jurídica sobre el alcance del hecho mismo de la ilegalidad"27. Esto parece lo más coherente con un sistema que no sea formalista.

Otra cosa es el parámetro preciso que se use para la calificación de la invalidez. Esto es relevante porque se trata de la vara con que se medirá la validez o invalidez de los actos. Su determinación no puede hacerse en abstracto, porque cada ordenamiento lo determina de acuerdo a aquello que busca proteger a través de lo que normalmente se denominan causas o motivos de nulidad. Sin embargo, es posible constatar que en sistemas procesales evolucionados una buena parte de estos parámetros dice relación con las consecuencias que el acto defectuoso produce en la esfera de los derechos del afectado. Sea a través de un parámetro constitucional o de simple protección de intereses, como el parámetro del perjuicio, la forma de valorar la gravedad del defecto es por sus consecuencias, sean estas potenciales o efectivas.

El que el tipo de análisis que deba hacerse respecto del acto irregular sea relativo a sus efectos en el proceso produce que se trate de un examen dinámico que mira al acto en el contexto de este y que no atiende ya a su morfología, en contraste con el análisis estático que hace para determinar si el acto es irregular, lo que hace que el nivel de separación del acto con su modelo sea, al menos, poco relevante ${ }^{28}$. Ha de considerarse al acto en el contexto del proceso en que se ha insertado, o pretende insertarse, para determinar, o al menos pronosticar, qué tipo de consecuencias genera o puede generar en él.

\footnotetext{
27 En Beladiez (1994) 10. Consideraciones similares hacen Hernández (1995) 48; Andrés (2005) 61; y Barona Villar, S. en Montero et al. (2008) 423.

28 Marelli, Fabio (2000) La conservazione degli atti invalidi nel processo civile. Padova: Cedam, p. 49.
} 
Un juicio dinámico como el planteado necesariamente debe ser particular, pues cada una las especialidades del caso concreto deben ser consideradas para precisar si el resultado del defecto afecta aquello que se pretende proteger ${ }^{29}$. Ello lleva a que las fórmulas generales de determinación estén condenadas a ser infructuosas, más allá de su utilidad meramente ilustrativa.

\section{3) CASOS EN LOS QUE LA IRREGULARIDAD EQUIVALE A LA INVALI- DEZ}

En las situaciones más típicas de invalidez de los actos procesales, el esquema que se ha planteado se cumple, en lo descrito hasta el momento, en su totalidad. Sin embargo, en otras ocasiones, el juicio es más simple y meramente objetivo. En ellas, la irregularidad procesal implica la invalidez, sin que sea necesario un juicio de relevancia acerca de las consecuencias de la infracción causada o de su afectación de valores procesales. El solo apartamiento del modelo normativo basta, resultando irrelevantes alegaciones acerca de si se ha cumplido la finalidad del acto o de si se ha producido la vulneración de alguna garantía procesal concreta.

La existencia de este tipo de invalidez es algo en lo que la doctrina ha reparado desde hace un buen tiempo. Ya Alsina se refería a ellas como nulidades automáticas ${ }^{30}$, que serían una excepción a la regla del pas de $n u$ llité sans grief ${ }^{31}$. Más recientemente, RichaRD GonZÁLEZ se refiere a estas situaciones como casos de nulidad objetiva, debido a que se producen de la sola comparación entre la norma procesal general y la norma específica procesal $^{32}$.

La justificación de existencia de este tipo de normas es algo que no se puede realizar en forma genérica. En cada caso parece haber un fundamento distinto que puede ir desde la protección de garantías constitucionales, hasta simples opciones de política legislativa que busquen reforzar el cumplimiento de un requisito en particular ${ }^{33}$. La determinación de la justificación tiene solo trascendencia especulativa, pues no incide en la

\footnotetext{
29 Bedaque (2010) 624.

30 La denominación no es del todo afortunada, porque la existencia de una invalidez objetiva no supone necesariamente la nulidad. Que los juicios de regularidad y validez se consoliden como uno solo no supone que necesariamente el acto deba ser nulo, porque perfectamente podrían operar las figuras de la convalidación y subsanación. Cabría, entonces, hablar de invalidez automática, pero no de nulidad automática.

31 Alsina, Hugo (1958) Las nulidades en el proceso civil. Buenos Aires: Ediciones Jurídicas Europa-América, p. 73.

32 Richard González, Manuel (2008) Tratamiento procesal de la nulidad de actuaciones. Cizur Menor, Navarra: Aranzadi, p. 18.

33 De la opinión contraria es Yelamos Bayarri, Estela (2006) Nulidad procesal y comunicaciones judiciales fallidas. Barcelona: Atelier, p. 84, quien sostiene que toda nulidad tiene por objeto la protección de una garantía constitucional.
} 
apreciación de la validez. Si consisten o no en una presunción de derecho de afectación de una garantía u otra cosa es irrelevante ${ }^{34}$. Desde el momento en que se objetiva la causal, sacando un criterio de valoración de la misma que exceda la sola apreciación de la infracción del modelo, la forma propiamente tal se transforma en un objeto de protección autónomo que debe ser tutelado sin entrar en consideraciones ulteriores ${ }^{35}$.

Desde el punto de vista hermenéutico, la dificultad de esta especie de invalidez pasa por reconocerla en un CPC en el que no aparece de forma expresa. Hay diversos casos diseminados por él en que, en general, se admite su existencia, como la falta de autorización de las actuaciones judiciales por el ministro de fe respectivo (artículo 61), la incompetencia del tribunal, la intervención de un juez implicado o con recusación declarada o pendiente o los fallos adoptados por tribunales colegiados integrados en contravención a la ley (artículo $768 n^{\circ} 1,2$ y 3), entre otros. Otros, sin embargo, resultan más discutibles, como la falta de conciliación ${ }^{36}$ o la omisión resolución que cita a las partes a oír sentencia (795 no 2 y 7 , en relación con el artículo $768 n^{\circ}$ 9). Partiendo de la idea de que se trata de una situación excepcional, la clave debiese estar en saber identificar la ratio legis tras cada norma, para determinar si ella se satisface con una protección relacionada con la afectación de derechos de la contraria o requiere una protección absoluta, que prescinda de esa consideración.

\section{4) LA INEFICACIA}

\section{1) NOCIÓN Y DISTINCIÓN DE LA INVALIDEZ}

Se dice que un acto es ineficaz cuando se ve privado de sus efectos normales $^{37}$. Expresada así, se descarta que equivalga a la eliminación jurídica absoluta del acto. Jurídicamente el acto se reputa realizado, solo que no ha producido todos sus efectos. Las consecuencias que se esperaba que tuviese

34 Tavolari Oliveros, Raúl (1994). "Reflexiones actuales sobre la nulidad procesal”. Revista de Derecho y Jurisprudencia y Gaceta de los Tribunales, N XCI. 11, con otra nomenclatura, insta por la inclusión de la noción de perjuicio incluso en aquellos casos que identifica como de nulidad absoluta, agregando que "Me parece que en aquellos casos en que por razones de política legislativa se entienda inevitable la declaración de nulidad, la forma que concilie estas motivaciones será la de presumir de derecho que determinadas infracciones o vicios irrogan perjuicios"

35 Así lo hace notar, respecto de la intervención preceptiva del secretario en determinadas actuaciones, Hernández (1995) 197.

36 A favor de una consideración objetiva de ella, Tavolari Oliveros, Raúl (1996) Nuevo régimen de los recursos de casación y queja. Santiago de Chile: ConoSur, p. 57.

37 Maurino, Alberto L. (2001) Nulidades procesales. Buenos Aires: Astrea, p. 313. 
en cuanto acto procesal regular, no las tiene, pero sí puede tener otras ${ }^{38}$. Por ello, decir que la anulación de un acto lleva a la eliminación absoluta de este es una exageración, porque seguirá siendo un acto dentro del proceso que será considerado en algunos aspectos. Así, por ejemplo, una sentencia que es anulada genera efectos, como el de configurar una causa de implicancia del juez que ha fallado el asunto (artículo 195 no 8 COT).

Aunque es común su uso como sinónimos, es indispensable diferenciar la ineficacia de la invalidez. En el derecho sustantivo, aunque con algunas objeciones, esta diferenciación se reconoce especialmente a partir de Windscheid ${ }^{39}$, quien afirma que, en un negocio jurídico, la invalidez se origina en la falta de alguno de sus requisitos y que, como consecuencia de eso, el derecho no le reconoce la fuerza de producir la conformación de la relación. Sería un concepto más restringido que el de la ineficacia, pues un negocio puede ser ineficaz aun sin ser defectuoso ${ }^{40}$.

Como se decía, el juicio de validez implica, en el fondo, diferenciar los actos a los que debe darse protección jurídica de los que no. En otras palabras, diferenciar los actos que deben producir sus efectos normales de aquellos que deben ser privados de estos como una forma de excluirlos del tráfico jurídico. En este punto se produce normalmente el equívoco de buena parte de la doctrina, al pasar de afirmar que un acto no debe producir efectos, por ser inválido, a decir que no produce efectos, es decir, al pasar del campo de prescriptivo al descriptivo, pues se daría una equivalencia entre la invalidez y la ineficacia que en los hechos no exis$\mathrm{te}^{41}$. Tomando esta falta de equivalencia, se constata que:

a. Hay actos válidos ineficaces y actos inválidos eficaces ${ }^{42}$. Ejemplos de la primera especie serían, entre otros, la sentencia anulada como

38 Entre otros, Morón Palomino, Manuel (1957) La nulidad en el proceso civil español. Barcelona: Ahr, p. 21; Dentr, Vittorio (1957). "Nullità degli atti processuale civili". Novissimo Digesto Italiano, XI, p. 472.; y Liebman, Enrico T. (2002) Manuale di diritto processuale civile: Principi. Milano: A. Giuffrè, p. 233.

39 De Castro y Bravo, Federico (1967) El negocio jurídico. Madrid: Instituto Nacional de Estudios Jurídicos, p. 463.

40 Windscheid, Bernhard (1930) Diritto delle pandette. Traducción de Fadda, Carlo y Bensa, Paolo. Torino: Unione Tipografico-Editrice Torinese, p. 264.

41 Buen ejemplo de esta confusión es Serra Domínguez, cuando sostiene que "Si por eficacia de un acto entendemos la producción de efectos jurídicos previstos para el acto mismo por el ordenamiento jurídico positivo y habida cuenta de lo dispuesto en los artículos anteriormente citados, todo acto procesal solo es susceptible de producir efectos cuando se realiza en la forma prevista por la ley; los actos procesales serán ineficaces cuando por faltarles algunos de los presupuestos, requisitos o condiciones previstos en la Ley procesal correspondiente no sean susceptibles de producir sus efectos normales" [en SERRA Domínguez, Manuel (1969). "Actos procesales ineficaces". En Estudios de derecho procesal. Barcelona: Ariel, p. 460, la cursiva ha sido agregada].

42 Una constatación similar se puede encontrar explícitamente en Luiso, Francesco P. (2007) Diritto processuale civile. Milano: Giuffrè, p. 402, quien distingue entre actos válidos y eficaces, válidos e ineficaces, inválidos y eficaces e inválidos e ineficaces. 
consecuencia de acogerse un recurso casación en el fondo (785 CPC) o la prueba rendida sobre un hecho de prueba posteriormente eliminado como consecuencia de acogerse una apelación respecto de la resolución que recibe la causa a prueba $(339$, inc. final, in fine). En la segunda especie encontramos, al acto convalidado y al acto subsanado ${ }^{43} ; y$

b. La invalidez es una calificación meramente teórica, derivada del desajuste entre la estructura real del acto y la estructura tipo normativa, mientras que la ineficacia es un dato empírico que nace de la constatación de si el acto ha producido efectos, con independencia de su origen ${ }^{44}$. Ilustrativamente, Santamaría Pastor afirma que "el acto inválido no es 'jurídicamente inexistente', en cuanto constituye una realidad fáctica que el ordenamiento ha de tener en cuenta para negarle valor de atendibilidad jurídica; ni es tampoco el que 'no produce efectos', sino el que carece de vigor para exigir jurídicamente la realización de tales efectos típicos, y cuyos efectos eventualmente producidos de facto pueden ser eliminados mediante una acción restauradora del orden jurídico" ${ }^{45}$.

\section{2) EL PASO DE LA INVALIDEZ A LA INEFICACIA}

\subsection{1) No toda invalidez implica ineficacia}

La diferenciación entre invalidez e ineficacia no solo se da por los planos en que opera una y otra, también por la relación contingente que sostienen, la cual, como se decía, hace que un acto pueda ser válido pero ineficaz o inválido y eficaz. Esta última hipótesis es la que más nos interesa, debido a que se verifica cuando se dan dos figuras que tampoco se han delimitado claramente, pero que tienen importancia sustancial: la subsanación y la convalidación.

Aunque la distinción pueda parecer algo forzada, cabe diferenciar a ambas figuras. Siguiendo al uso que hace de ella la jurisprudencia espa-

43 En este sentido, Lourido Rico afirma que la causa de la ineficacia "puede ser la invalidez del acto, a la que se le suele llamar causa intrínseca, o bien cualquier otra causa extrínseca, como, por ejemplo, el incumplimiento de una condición o la falta de un acto posterior que ha de unirse al primero para que este despliegue su normal eficacia” [en Lourido Rico, Ana M. (2003) La nulidad de actuaciones: Una perspectiva procesal. Granada: Comares, p. 37]. Hoy esta distinción parece estar bastante asentada en la mayor parte de la doctrina. En el mismo sentido, Fontr, Rosella (2008) L'inammissibilità degli atti processuali penali. Padova: Cedam, p. 8; y Didier JR., Fredie (2005). "El juicio de admisibilidad en la teoría general del derecho". Revista Iberoamericana de Derecho Procesal, No 8, p. 129.

44 Santamaría Pastor, Juan A. (1972) La nulidad de pleno derecho de los actos administrativos: Contribución a una teoría de la ineficacia en derecho público. Madrid: Instituto de Estudios Administrativos, p. 158.

45 SANTAMARÍA (1972) 162 
ñola, que la ha dotado de una preponderancia que no tiene parangón en otro ordenamiento jurídico ${ }^{46}$, entenderemos por subsanación como la corrección o integración de un acto procesal defectuoso, realizada normalmente por el mismo autor de este, sea este el órgano jurisdiccional o una de las partes. En este caso, la invalidez desaparece sin necesidad de eliminar al acto y sus efectos, a través de suprimir la afectación que causa el vicio presente en él. Nótese que, aunque lo común será que el acto se subsane realizando aquello que se omitió o se realizó imperfectamente (por ejemplo, firmar el escrito o incluir en la sentencia un pronunciamiento que no se había hecho), lo efectivamente relevante no es la eliminación del defecto, sino de la afectación que este causa, sea por la vía de cumplir aquello que no se había cumplido, como por otra que produzca el mismo remedio.

A su vez, entendemos como convalidación a la aceptación de un defecto por parte de quien se ha visto afectado por ella. Esta puede ser expresa, cuando se realiza en términos formales y explícitos, o tácita, tanto cuando precluye la posibilidad de impetrar la nulidad como cuando se realice un acto que suponga la renuncia a impetrar la nulidad. En este caso, la invalidez desaparece no por la eliminación del defecto, sino por la falta de interés de poner en relieve la nulidad por quien se ha visto afectado por ella.

Aunque es claro que ambas técnicas tienen límites, cuestión que hace que no todos los actos sean subsanables y convalidables, no está demasiado claro cuáles son, por la ausencia de tratamiento del tema en nuestra doctrina. Aunque en esta ocasión no se profundice más en el tema, se debe dejar sentada una premisa: los límites de ambas técnicas no son los mismos. Mientras el que un acto sea subsanable dependerá básicamente del diseño que se haga del procedimiento y de las características del defecto a superar, la convalidación dependerá del interés público que esté involucrado en el tema y del rol que se dé al juez en el control de la validez de los actos. Así, por ejemplo, la invalidez que genera la falta de autorización de una actuación procesal por el ministro de fe respectivo debe entenderse no susceptible de ser convalidada, pero perfectamente subsanable por una autorización posterior. Por el contrario, una notificación por cédula

46 Díez-Picazo Giménez, Ignacio (1998). "El artículo 24 de la Constitución y la aplicación del derecho procesal: Breve reflexión sobre algunas cuestiones pendientes en la interpretación de un precepto capital”. En Martínez-Simancas Sánchez, Julián y Aragón Reyes, Manuel (coordinadores): La Constitución y la práctica del Derecho, Vol. 1. Madrid: Sopec, p. 341-360, sostiene que "La ampliación, cuando no lisa y llanamente la introducción, de la técnica de la subsanación puede ser estimada sin exageración como una de las grandes contribuciones de la jurisprudencia constitucional sobre el derecho a la tutela judicial efectiva. A partir de la misma, no solo se ha generalizado en nuestra cultura forense la técnica sanatoria, sino que por obra de sucesivas reformas procesales se han introducido normas sobre supuestos y procedimientos de subsanación de defectos procesales". 
efectuada a una persona en un domicilio que no corresponde no es subsanable, porque sería necesario realizar una nueva notificación, pero es perfectamente convalidable por el afectado al darse por enterado de lo que se le pretendía comunicar.

Aun con sus diferencias, la subsanación y la convalidación operan en el mismo momento, una vez que el juicio de validez ha sido desfavorable $\mathrm{y}$ antes de que se produzca la ineficacia del acto. Aunque no haya cabal conciencia de ello, en nuestro derecho procesal civil ambas técnicas operan con preferencia a la de la nulidad. En otras palabras, la nulidad solo es procedente a falta de subsanación y convalidación. En esta última, ello es claro en todos los casos en que procede, pues la nulidad de oficio, se debe entender aplicable cuando la nulidad es inconvalidable ${ }^{47}$. En la subsanación, se debe entender implícita esa preferencia en la exigencia para que proceda la nulidad de que el perjuicio solo reparable por la vía de la nulidad, formulada en los artículos 83 inc. $1^{\circ}$ y 768 inc. $3^{\circ} \mathrm{CPC}$.

\subsection{2) Formas de implementar la ineficacia}

La forma de articular la ineficacia de un acto inválido, es decir, el nexo entre la potencialidad de la invalidez y la realidad de la ineficacia, se realiza a partir de las técnicas instrumentales que cada ordenamiento contempla. Una de ellas es la nulidad. Siendo solo una técnica de instrumentación de la ineficacia, resulta impropio hablar de actos nulos o anulables como sinónimo de actos inválidos o de ineficaces ${ }^{48}$, pues, como se verá a continuación, la relación entre la nulidad y estos dos conceptos no es necesaria.

La nulidad no siempre supone hacer ineficaz un acto inválido. En ocasiones, la nulidad se aplica a actos válidos, pero que se estiman jurídicamente desacertados. Por simple técnica legislativa, se ha preferido anular que revocar. Es lo que ocurre en nuestro ordenamiento procesal civil con el recurso de casación en el fondo, que permite anular sentencias perfectamente válidas, si en ellas hay una infracción de ley que influye sustancialmente en lo dispositivo del fallo (767 CPC) o con los recursos de nulidad existentes en materia procesal penal y laboral que, conjuntamente con motivos auténticamente de invalidez, incluyen nociones que están encaminadas a revisar la corrección de la sentencia y no la validez de esta o del procedimiento que la ha precedido ${ }^{49}$.

\footnotetext{
47 Tavolari (1994) 6 y ss.; Salas Vivaldi, Julio E. (2000) Los incidentes: y en especial el de nulidad en el proceso civil, penal y laboral. $7^{\text {a }}$ edición. Santiago Chile: Editorial Jurídica de Chile, p. 123.

48 SANTAMARÍA (1972) 168.

49 El artículo 373, letra b, Código Procesal Penal establece como motivo de nulidad "la errónea aplicación del derecho que haya influido sustancialmente en lo dispositivo del
} 
Por el contrario, habrá casos en los que el paso de la invalidez a la ineficacia se hará con otra técnica, como lo puede ser, en el caso de nuestro ordenamiento, la inadmisión ${ }^{50}$. Aunque no sea propiamente el objeto de este estudio, es necesario dejar sentado que la inadmisión es un técnica de control de los actos de parte que, entre otros objetivos, tiene el de controlar in limine su validez, impidiendo la incorporación al proceso de actos defectuosos. La nulidad, en contraste, solo es una técnica idónea para eliminar actuaciones judiciales y no de parte ${ }^{51}$. La nulidad afecta actos de parte solo cuando ellos ya han sido incorporados al proceso, y lo hace de forma indirecta, pues no es posible, por ejemplo, anular una demanda, sino solo la resolución que la admite, cayendo esta solo por un efecto reAlejo ${ }^{52}$.

Entendidas como técnicas necesarias para la implementación de la invalidez en ineficacia, se puede apreciar que ambas se basan en un mismo juicio de validez ${ }^{53}$. El tipo de enjuiciamiento que se hace es el mismo y van en la línea ya latamente explicada: verificada la existencia de una irregularidad, debe analizarse si la misma provoca, de acuerdo a los estándares de cada sistema, una afectación de suficiente entidad como para que el ordenamiento no le preste su protección. Siendo la inadmisión un asunto tan escasamente desarrollado desde el punto de vista legislativo, la constatación de que la nulidad y la inadmisión tienen un punto de partida común, la invalidez, tiene una enorme relevancia interpretativa, debido a que permite sostener la aplicación de las normas y principios de la nulidad a la inadmisión en la medida que no pugnen con las características de ella ${ }^{54}$.

La identidad de juicio, sin embargo, no supone una identidad de motivos o causas entre la inadmisión y la nulidad ${ }^{55}$. En este aspecto, la

fallo”, mientras que el artículo 477 del Código del Trabajo, replicando a la casación civil, establece como causal de nulidad la infracción de ley que haya influido sustancialmente en lo dispositivo del fallo.

50 Se suele relacionar la inadmisión con la nulidad, en especial cuando no se deslinda bien esta última de la invalidez. Así, por ejemplo, Maier, Julio B. J. (1980) Función normativa de la nulidad. Buenos Aires: Depalma, p. 141, habla de la admisibilidad como otra forma de aparición o de hacer efectiva la nulidad y Bedaque (2010) 714, de ella como una especie de "nulidad a priori".

51 Esta es la postura sostenida, entre otros, por Hernández (1995) 204; Andrés (2005) 135; y Yelamos (2006) 74.

52 HERNÁNDEZ (1995) 109.

53 Por todos, Mancinelli (1957) 487; Maier (1980) 141 y Fonti (2008) 29. En contra de esta postura, Pérez Ragone, Álvaro (2010). “¿Presupuestos procesales? Admisbilidad y fundabilidad en la dogmática procesal civil alemana: Revisión contemporánea”. Revista do Programa de Pós-Graduação em Direito do Universidade Federal da Bahia, No 20, Vol. I, p. 208, quien, sin explicarlo, sostiene que son cuestiones diversas.

54 En el mismo sentido, Didier (2005) 146.

55 Bedaque (2010) 714. 
coincidencia es solo parcial, lo que implica que no toda causa de nulidad es de inadmisión ni viceversa.

No todo motivo de nulidad es, a la vez, de inadmisión, debido a que los defectos procesales que solo puedan afectar a las actuaciones del órgano judicial, y no a los actos de partes, podrán generar nulidad solamente. Así, por ejemplo, la falta de motivación de una resolución o la dictación de ella por un juez que por cualquier razón sea incompetente son motivos de invalidez respecto de resoluciones judiciales y nunca podrán ser dejados sin efecto a través de la inadmisión.

En el sentido contrario, la situación más evidente de motivos de inadmisión que no son de nulidad está dada por aquella faceta de la inadmisión como instrumento de rechazo in limine por motivos de fondo y no meramente procesales ${ }^{56}$. En estos casos, la admisión inadecuada no devendrá en la nulidad de lo actuado, sino en la desestimación de la pretensión formulada. No existiendo problemas de validez, no sería la nulidad un instrumento idóneo para hacerse cargo de este tipo de defectos. Si se busca ahorrar la tramitación de una determinada pretensión que carece de fundamento, sería incluso contraproducente para el fin que se busca debido a que la ineficacia generada permitiría que se volviese a plantear aquella cuestión improcedente.

\subsection{3) Alcance de la ineficacia: la nulidad derivada y el principio de conservación}

El plano en el que opere la ineficacia incide en su fuerza difusiva. Así, en el caso de la inadmisión, al impedir el ingreso del acto de parte al proceso, esta opera solo respecto del acto, sin ulteriores consecuencias en cuanto a la eficacia de otros actos.

Por el contrario, la ineficacia que genera la nulidad afecta al propio acto defectuoso, pero también a aquellos conexos con él, al punto de que determinados vicios pueden, incluso, terminar en la nulidad de todo el procedimiento. Como el acto nulo no puede producir los efectos de un acto normal, todas las actuaciones que sigan a él y que sean su consecuencia deben ser declaradas ineficaces. Este fenómeno es el que se conoce como la nulidad derivada, que supone la ineficacia de actuaciones poste-

56 Nuestra doctrina no suele aceptar esta posibilidad, al menos respecto de la figura de la manifiesta falta de fundamento, del artículo 782, inciso $2^{\circ}$ CPC. A partir del hecho que la norma habla de rechazo y no de inadmisión, se ha entendido que no se trataría de un supuesto de inadmisión por motivos de mérito [en este sentido, Libedinsky Tschorne, Marco (1995). "La manifiesta falta de fundamento en el recurso de casación en el fondo". Gaceta Jurídica, No 183, p. 9.; y TaVolari (1994) 38]. La cuestión, como está planteada, no es más que de denominaciones, porque en cualquier caso se trata de un rechazo in limine que, si no se le llama inadmisión es solo para preservar la vieja distinción entre fundabilidad y admisibilidad. 
riores relacionadas con el acto nulo como una manera de implementar a cabalidad las consecuencias de anulación dispuesta.

La expansión de la nulidad a otros actos tiene, sin embargo, un importante contrapeso en el principio de conservación, que, partiendo de la idea que la ineficacia generada por la nulidad se extiende a otras actuaciones posteriores, insta a resguardar todo aquello que sea posible, es decir, a extender la ineficacia a los casos estrictamente necesarios. La tensión entre estos dos principios -que son como dos caras de una misma moneda- es la que termina por configurar el alcance de la nulidad. La idea es anular todo lo necesario para hacer efectivamente ineficaz el acto inválido, pero sin afectar otros actos que no estén relacionados.

\subsubsection{1) La nulidad derivada}

La concatenación que existe entre todos los actos procesales hace que la invalidez de uno de ellos sea una verdadera epidemia que afecta a los actos posteriores ${ }^{57}$. La presencia de cualquier acto inválido provoca que aquellos otros actos que se relacionan más estrechamente con él se contaminen y, al momento de implementar esta ineficacia a través de la nulidad, también se vean afectados.

El alcance de este fenómeno de la nulidad derivada es aplicable tanto a los actos de parte como a los actos del tribunal ${ }^{58}$. Así, un acto de parte que ha sido admitido erróneamente ingresa al sistema una invalidez que afectará a otros. Lo mismo ocurre si es un acto del tribunal. En ambos casos, los actos que ven afectada su validez pueden también ser de una especie u otra. La única diferencia es que una vez que se ha ingresado el acto de parte al proceso, la forma de eliminar el defecto no es propiamente anulándolo, sino anulando la resolución judicial que lo ha admitido, produciendo la consecuencial exclusión del acto de parte desde ese momento del proceso.

Para que propiamente se pueda hablar de nulidad derivada es necesario que estemos frente a un acto válido ${ }^{59}$ que no presenta defectos invalidantes en sí, sino que se ve afectado en su eficacia por su relación con otro sí inválido. Este acto deberá ser posterior al defectuoso, en caso alguno puede ser anterior ${ }^{60}$. La invalidez, como los ríos, desciende, pero no remonta.

La fuerza expansiva de la nulidad no dependerá ni de la entidad ni de la gravedad del defecto, sino del lugar en donde se encuentre en el

\footnotetext{
57 Liebman (2002) 235; Binder (2000) 112.

58 De hecho, Peyron, Carlo (1958). "Inammissibilità". Enciclopedia del Diritto, Vol. XXII, p. 619., advierte que la inadmisibilidad tiene una "particolare forza diffusiva".

59 Morón (1957) 199.

60 Mancinelli (1957) 492.
} 
proceso $^{61}$. Es por ello que los presentes en la demanda son más graves en cuanto a su repercusión en el proceso, al ser el acto inicial del juicio, un defecto en ella significa la invalidación de todo lo obrado ${ }^{62}$. Sin embargo, es cierto, que en ese acto en particular, por ser el que funda el proceso, resume dentro de sus requisitos y presupuestos una exigencia bastante mayor, cuya ausencia pone en riesgo todo el procedimiento.

\subsubsection{2) El principio de conservación}

La doctrina ha entendido el principio de conservación de dos maneras. La primera, más amplia, lo identifica con la máxima de promover el menor uso posible de la nulidad dentro de un proceso y con la menor fuerza difusiva posible. En esta concepción, la subsanación y la convalidación se consideran como una expresión de aquel principio, en cuanto evitan el uso de la nulidad ${ }^{63}$.

La segunda forma de entenderlo es diferenciándolo de la subsanación y la convalidación, dejando en él solo la premisa de que se anulen los actos estrictamente necesarios en caso de decretarse una nulidad. En este sentido, el objetivo del principio de conservación sería modular la nulidad derivada, partiendo de la idea de que no necesariamente todos los actos posteriores deben verse afectados por la nulidad de un acto que le antecede ${ }^{64}$.

Aunque la primera opción parece razonable, considerando que es efectivo que el legislador ha buscado emplear lo menos posible la nulidad, y que a eso se le puede llamar perfectamente conservación, parece mejor utilizar el término en el segundo sentido, que calza mejor con el hecho de que la subsanación y la conservación en sentido estricto operan en hipótesis distintas. Mientras la primera impide la nulidad, la segunda la supone para siquiera actuar, lo que quiere decir que, en circunstancias normales, no son compatibles ${ }^{65}$.

Considerado en este segundo sentido, el principio de conservación tiene como punto de partida el que la nulidad de un acto no necesaria-

\footnotetext{
61 En un sentido similar, MaUrino (2001) 315.

62 LiEBMAN (2002) 235.

63 Martín de la Leona, José María (1996) La nulidad de las actuaciones en el proceso civil. Madrid: Colex, p. 334; Marelli (2000) 148 y ss.

64 Gur Mori, Tomás (1988). "La intercambiabilidad de las técnicas jurídicas: Los principios de proporcionalidad, conservación y subsanación como emanación del de tutela activa". La Ley: Revista jurídica española de doctrina, jurisprudencia y bibliografía, Vol. 3, p. 959; BonET Navarro, Ángel (1993) "Subsanación de defectos procesales y conservación de actos en el proceso civil”. En La nulidad de actuaciones en el proceso civil. Madrid: Consejo General de Poder Judicial, p. 365; Richard (2008) 92.

Richard GonzÁlez (2008) 92.
} 
mente tiene que implicar la nulidad de todos los que le sucedan 66 . Para la afectación de estos, no solo debe haber una relación cronológica (ser posteriores), además debe existir una relación causal, un vínculo entre los actos que justifique la anulación ${ }^{67}$, que es lo expresado por el aforismo "utile per inutile non vitiatur". El problema radica en cómo determinar cuáles actos deben ser afectados y cuáles no, porque en un proceso-como subraya Ramos Méndez- todos los actos tienen algún grado de encadenamiento, haciendo que, en definitiva, la determinación dependa de criterios principalmente de economía procesal o de proporcionalidad ${ }^{68}$.

Nuestro CPC sienta el principio de la conservación al señalar que la declaración de nulidad de un acto no supone la ineficacia de todo lo obrado (art. 83, inc. final CPC). A partir de la idea de que la nulidad tiene la fuerza expansiva que recién se explicaba, se advierte que no es una cuestión absoluta, dejando en manos del juez la determinación precisa de los actos que deben ser anulados. A partir de ello, se ha sostenido por la doctrina que la nulidad no afecta al acto que es independiente del afectado por el defecto, debiendo anularse solo aquellos que se encuentran íntimamente ligados a él ${ }^{69}$.

Esta exigencia de independencia claramente se cumple respecto de actos que no se encuentran en una secuencia lineal con el acto nulo. En algún sentido, son actos que han corrido por carriles paralelos, no estando condicionada la práctica del acto conservado por el del nulo, por no ser el último presupuesto del primero. Así, por ejemplo, en un caso de litisconsorcio pasivo, la nulidad del emplazamiento de uno de los demandados no afecta la eficacia del emplazamiento de otro de ellos, aunque fuese posterior, o la anulación de la declaración de un testigo no anula la de los $\operatorname{otros}^{70}$.

Más discutible es la situación de los actos secuencialmente dependientes, pero independientes en su contenido. Se trata de actos que están en la línea del acto nulo, por lo que, en principio, se afectan por su nulidad, pero cuyo contenido no se encuentra determinado por el del acto inválido. Piénsese en un juicio con dos demandados, Pedro y Juan, en el que Pedro ha comparecido y contestado la demanda, mientras que Juan se encuentra en rebeldía. Si se llegara a anular por falta de emplazamiento todo lo obrado, dejándose la causa en estado de notificarse nuevamente, ¿sería ineficaz la contestación de Juan?, ¿y el mandato conferido en ese mismo escrito? Si se aplica estrictamente la regla de la línea secuencial, no

Gui (1988) 953.

Mancinelli (1957) 492; Liebman (2002) 235.

Ramos Méndez, Francisco (2008) Enjuiciamiento civil: Cómo gestionar los litigios civiles, Vol. II. Barcelona: Atelier, p. 1420.

69 Tavolari (1994) 14; Salas (2000) 82.

70 Maurino (2001) 317. 
cabría duda en ambos casos. Es, no obstante, razonable puedan preservar su eficacia, si se alude a la existencia de un principio favorable a la conservación de las actuaciones.

\section{5) CONCLUSIONES}

a. Cabe diferenciar la irregularidad, la invalidez y la ineficacia. La irregularidad es la simple separación de un acto procesal determinado de su modelo legal. La invalidez, por su parte, es el resultado de un juicio de valor que se hace respecto de actos irregulares, en virtud del cual se estima que el mismo no debe ser protegido por el derecho debido a las afectaciones que producen sus defectos. La ineficacia es la simple privación de sus efectos normales a un determinado acto procesal, sea consecuencia de su invalidez o de otro tipo de circunstancias.

b. La irregularidad se determina mediante el contraste entre el acto concreto y el modelo que para él entrega el ordenamiento jurídico, modelo que debe ser reconstruido considerando la integración del acto en el proceso y los derechos fundamentales de rango constitucional.

c. Aunque son cuestiones diversas, toda invalidez presupone la irregularidad de actos, pues el acto regular necesariamente es válido, estatus que se explica a partir de la incorporación al modelo ideal de acto de los estándares que, a criterio del legislador, son suficientes para garantizar el respeto a los valores más relevantes del sistema.

d. El parámetro que determina la invalidez de los actos constituye una opción política que puede cambiar de un ordenamiento a otro, en atención a los que se estiman los valores más dignos de protección para cada sociedad. La tendencia es a que ese estándar se relacione con los derechos fundamentales de carácter procesal.

e. El hecho de que un acto sea inválido no implica que deba devenir en ineficaz, toda vez que hay actos inválidos que terminan por ser eficaces, producto de su subsanación o convalidación, técnicas superadoras de los defectos procesales que son preferentes a la nulidad o a la inadmisión.

f. La nulidad es una de las formas de implementar la ineficacia, como también lo es la inadmisión. Ellas se diferencian pues operan respecto a distintos tipos de actos. Mientras la nulidad es solo predicable de actuaciones judiciales, la inadmisión lo es respecto de actos de parte.

g. A diferencia de la inadmisión, la nulidad tiene fuerza difusiva, que se traduce en la afectación de los actos válidos que, en la concatenación 
propia de los actos procesales, dependen de él. Esta fuerza difusiva se morigera a partir del principio de conservación, que es una forma de atenuar los alcances de ese efecto difusivo.

\section{6) Bibliografía CiTADA}

- Alsina, Hugo (1958) Las nulidades en el proceso civil. Buenos Aires: Ediciones Jurídicas Europa-América.

- Andrés Ciurana, Baldomero (2005) La invalidez de las actuaciones en el proceso civil. Valencia: Tirant lo Blanch.

- Bedaque, José d. S. (2010) Efectividad del proceso y técnica procesal. Traducción: Monroy Palacios, Juan José y Delgado Suárez, Christian. Lima: Communitas.

- Beladiez Rojo, Margarita (1994) Validez y eficacia de los actos administrativos. Madrid: Marcial Pons.

- Binder, Alberto M. (2000) El incumplimiento de las formas procesales: Elementos para una critica a la teoria unitaria de las nulidades en el proceso penal. Buenos Aires: Ad-Hoc.

- Bonet Navarro, Ángel (1993). "Subsanación de defectos procesales y conservación de actos en el proceso civil”. En La nulidad de actuaciones en el proceso civil. Madrid: Consejo General de Poder Judicial, p. 345-408.

- Carnelutti, Francesco (1999) Lecciones sobre el proceso penal. Traducción: Sentís Melendo. Buenos Aires: El Foro.

- Carrasco Poblete, Jaime (2011). "La nulidad procesal como técnica protectora de los derechos y garantías de las partes en el derecho procesal chileno". Revista de Derecho Universidad Católica del Norte, Vol. 18, No 1, p. 49-84.

- Couture, Eduardo J. (2002) Fundamentos del derecho procesal civil. Montevideo: B de F.

- De Castro y Bravo, Federico (1967) El negocio jurídico. Madrid: Instituto Nacional de Estudios Jurídicos.

- Delgado Echeverría, Jesús (2006). "El concepto de validez de los actos jurídicos de derecho privado". Anuario de derecho civil, Vol. 58, No 1, p. 9-74.

- Di Geronimo, Paolo (2006) La nullità degli atti nel processo penale. Milano: Giuffrè.

- Didier Jr., Fredie (2005). "El juicio de admisibilidad en la teoría general del derecho". Revista Iberoamericana de Derecho Procesal, No 8, p.129-167.

- Díez-Picazo Giménez, Ignacio (1998). "El artículo 24 de la Constitución y la aplicación del derecho procesal: Breve reflexión sobre algunas cuestiones pendientes en la interpretación de un 
precepto capital”. En Martínez-Simancas Sánchez, Julián y Aragón Reyes, Manuel (coordinadores): La Constitución y la práctica del Derecho, Vol. 1. Madrid: Sopec, p. 341-360.

- Fontr, Rosella (2008) L'inammissibilità degli atti processuali penali. Padova: Cedam.

- Giovanardi, Carlo A. (1987). "Sullo scopo dell'atto processuale, in relazione alla disciplina della nullità". Rivista di diritto civile, II, p. 264-281.

- Gui Mori, Tomás (1988). "La intercambiabilidad de las técnicas jurídicas: Los principios de proporcionalidad, conservación y subsanación como emanación del de tutela activa”. La Ley: Revista jurídica española de doctrina, jurisprudencia y bibliografía, Vol. 3, pp. 946-960.

- Hernández Galilea, Jesús M. (1995) La nueva regulación de la nulidad procesal: El sistema de ineficacia de la LOPJ. Oviedo: Fórum.

- Libedinsky Tschorne, Marco (1995). "La manifiesta falta de fundamento en el recurso de casación en el fondo". Gaceta Jurídica, No 183, p. y ss.

- Liebman, Enrico T. (2002) Manuale di diritto processuale civile: Principi. 6a edición a cargo de Vittorio Colesanti, Elena Merlin, Edoardo F. Ricci. Milano: A. Giuffrè.

- Lourido Rico, Ana M. (2003) La nulidad de actuaciones: Una perspectiva procesal. 2a edición. Granada: Comares.

- Luiso, Francesco P. (2007) Diritto processuale civile. Milano: Giuffrè.

- Maier, Julio B. J. (1980) Función normativa de la nulidad. Buenos Aires: Depalma.

- Mancinelli, Roberto (1957). "Nullità degli atti processuali penali". Novissimo Digesto Italiano, XI. Torino: UTET, p. 486-492.

- Marelli, Fabio (2000) La conservazione degli atti invalidi nel processo civile. Padova: Cedam.

- Marinoni, Luiz G.; Pérez Ragone, Álvaro y Núñez Ojeda, Raúl (2010) Fundamentos del proceso civil: Hacia una teoría de la adjudicación. Santiago de Chile: Abeledo-Perrot.

- Martín de la Leona, José María (1996) La nulidad de las actuaciones en el proceso civil. Madrid: Colex.

- Maurino, Alberto L. (2001) Nulidades procesales. Buenos Aires: Astrea.

- Montero Aroca, Juan, et al. (2008) Derecho jurisdiccional, I. parte general. 16a edición. Valencia: Tirant lo Blanch.

- Morón Palomino, Manuel (1957) La nulidad en el proceso civil español. Barcelona: Ahr.

- Pérez Ragone, Álvaro (2010). “¿Presupuestos procesales? Admisibilidad y fundabilidad en la dogmática procesal civil alemana: 
Revisión contemporánea”. Revista do Programa de Pós-Graduação em Direito do Universidade Federal da Bahia, No 20, Vol. I, 183-208.

- Peyron, Carlo (1958). "Inammissibilità". Enciclopedia del Diritto, Vol. XXII. Milano: Giuffrè, p.612-617.

- Prieto-Castro y Ferrándiz, Leonardo (1988) Derecho procesal civil. Madrid: Tecnos.

- Ramos Méndez, Francisco (2005) El sistema procesal español. 7a edición. Barcelona: Atelier.

- Ramos Méndez, Francisco (2008) Enjuiciamiento civil: Cómo gestionar los litigios civiles, Vol. II. Barcelona: Atelier.

- Richard González, Manuel (2008) Tratamiento procesal de la nulidad de actuaciones. Cizur Menor, Navarra: Aranzadi.

- Vivaldi, Julio E. (2000) Los incidentes: y en especial el de nulidad en el proceso civil, penal y laboral. $7^{\text {a }}$ edición. Santiago Chile: Editorial Jurídica de Chile.

- Santamaría Pastor, Juan A. (1972) La nulidad de pleno derecho de los actos administrativos: Contribución a una teoría de la ineficacia en derecho público. Madrid: Instituto de Estudios Administrativo.

- Satta, Salvatore y Punzi, Carmine (1996) Diritto processuale civile. 12a edición. Padova: Cedam.

- Serra Domínguez, Manuel (1969) Estudios de derecho procesal. Barcelona: Ariel.

- Tavolari Oliveros, Raúl (1994). "Reflexiones actuales sobre la nulidad procesal". Revista de Derecho y Jurisprudencia y Gaceta de los Tribunales, No XCI, Vol. I, p. 1-15.

- Tavolari Oliveros, Raúl (1996) Nuevo régimen de los recursos de casación y queja. Santiago de Chile: ConoSur.

- Villar y Romero, José M. (1954). "Irregularidad y nulidad de los actos procesales administrativos". Revista de Derecho Procesal, Vol. 3, p. 317-341.

- Windscheid, Bernhard (1930) Diritto delle pandette. Traducción de Fadda, Carlo y Bensa, Paolo Emilio. Torino: Unione TipograficoEditrice Torinese.

- Yelamos Bayarri, Estela (2006) Nulidad procesal y comunicaciones judiciales fallidas. Barcelona: Atelier. 